\title{
Neonatal Partial Denervation Results in Nodal But Not Terminal Sprouting and a Decrease in Efficacy of Remaining Neuromuscular Junctions in Rat Soleus Muscle
}

\author{
Jane L. Lubischer and Wesley J. Thompson \\ Section of Neurobiology, School of Biological Sciences, Institute for Neuroscience and Institute for Cellular and Molecular \\ Biology, University of Texas, Austin, Texas 78712
}

\begin{abstract}
Mature motoneurons respond to partial denervation of their target muscle by sprouting to reinnervate denervated fibers, thus maintaining muscle strength in the face of motoneuronal loss caused by injury or disease. Neonatal motoneurons, however, do not expand to innervate more muscle fibers. The present work seeks to understand this developmental change in motoneuron response to partial denervation. It has been suggested that neonatal motor units cannot increase in size because they are already at their maximum size (approximately five times larger than in adulthood). We ruled out this explanation by showing that after partial denervation on postnatal day 14 (P14), when motor units have decreased to their adult size, motoneurons still did not sprout to reinnervate as many fibers as in adulthood. Instead, we found evidence supporting an alternative explanation involving terminal Schwann cells. After partial denervation of neonatal (but not adult) muscles, terminal
\end{abstract}

Schwann cells at denervated endplates undergo apoptosis. We found that terminal (but not nodal) sprouting was absent in partially denervated neonatal muscles. This finding suggests that terminal Schwann cells, previously reported to guide terminal sprouts to denervated endplates in adult muscles, are necessary for the formation and growth of terminal sprouts. Moreover, partial denervation on P14 severely weakened the remaining, uninjured synapses, suggesting that neonatal motoneurons may withdraw terminals after the denervation of nearby fibers. These findings have implications for the interpretation of previous studies on synapse elimination and offer insight into the failure of young motor units to expand after partial denervation.

Key words: Schwann cells; synapse elimination; NMJ; synaptic strength; development; motoneuron; curare
The ability of motoneurons to compensate for nerve injury is poor in early postnatal development. After partial denervation of adult muscle, the remaining motoneurons extend sprouts, some of which reinnervate denervated fibers (Hoffman, 1950). This results in an expansion of fourfold to fivefold in the number of fibers innervated by each motoneuron (i.e., an increase in motor unit size; Thompson and Jansen, 1977; Brown and Ironton, 1978; Gordon et al., 1993). Through this process, muscle strength can be maintained even after substantial loss of motoneurons due to injury or disease. In contrast, partial denervation within $7 \mathrm{~d}$ of birth results in little or no increase in motor unit size (Brown et al., 1976; Thompson and Jansen, 1977; Betz et al., 1980; Fisher et al., 1989). At this time in development, motoneurons have an expanded terminal arbor, and multiple motoneurons innervate each muscle fiber. During the first 2 weeks after birth, synapse elimination removes all but one synaptic input onto each fiber,

\footnotetext{
Received May 17, 1999; revised July 13, 1999; accepted Aug. 6, 1999.

This work was supported by National Institutes of Health National Research Service Award F32 NS09687 (J.L.L.) and National Institutes of Health Grant NS20480 (WJT). Antibody 2H3, developed by T. M. Jessell and J. Dodd, antibody SV2, developed by K. M. Buckley, and antibody G3G4, developed by S. J. Kaufman, were obtained from the Developmental Studies Hybridoma Bank maintained by the University of Iowa, Department of Biological Sciences, under contract N01-HD-73263 from the National Institute of Child Health and Human Development. Antibody P07 was kindly provided by Dr. Juan J. Archelos (University of Wurzburg). We thank L. A. Sutton for excellent technical assistance, G. E. Gage for help with graphics, and L. M. Hurley and G. T. Smith for helpful comments on this manuscript.

Correspondence should be addressed to Jane L. Lubischer, Section of Neurobiology, C0920, 140 Patterson Laboratory Building, University of Texas, Austin, TX 78712 .

Copyright (C) 1999 Society for Neuroscience $\quad 0270-6474 / 99 / 198931-14 \$ 05.00 / 0$
}

and each motor unit becomes smaller (Redfern, 1970; Brown et al., 1976; Jansen and Fladby, 1990). Partial denervations shortly after birth were originally performed to look for evidence of competition between terminals during synapse elimination (Brown et al., 1976; Thompson and Jansen, 1977; Betz et al., 1980). The few remaining motoneurons undergo little or no reduction in unit size in the absence of potential competition. Based on these experiments, it was concluded that competition among motoneurons drives the reduction in motor unit size during postnatal synapse elimination.

Left unexplained was why neonatal motoneurons do not expand and innervate denervated fibers. One explanation offered was that the units were already expanded beyond their adult size and could not maintain any more terminals (e.g., Brown et al., 1976; Thompson and Jansen, 1977). Recent experiments have suggested another possibility. After partial denervation of adult muscle, most $(\sim 70 \%)$ of the terminal sprouts that innervate denervated fibers grow along processes extended by Schwann cells present at denervated endplates (Son and Thompson, 1995b). In neonatal muscles, however, terminal Schwann cells quickly die by apoptosis after muscle denervation (Trachtenberg and Thompson, 1996). Thus, these Schwann cells would be unavailable to provide a stimulus or guide for terminal sprouts after neonatal partial denervation.

We now report that the inability of young motor units to expand after partial denervation cannot be explained by their already enlarged size but may be related to terminal Schwann cell death. We found that neonatal motoneurons, unlike mature motoneurons, do not extend terminal sprouts after partial denerva- 
tion. There is, however, nodal sprouting in the intramuscular nerves of young animals, where Schwann cells remain viable. These observations provide further evidence for the importance of Schwann cells in the motoneuronal sprouting response. Finally, we present evidence that neonatal partial denervation leads to severe morphological and physiological disruption of existing motoneuron terminals, a finding that influences the interpretation of previous studies of partial denervation during developmental synapse elimination.

Portions of this work have been reported previously in abstract form (Lubischer and Thompson, 1997).

\section{MATERIALS AND METHODS}

All experiments used rats bred and raised in the Animal Resources Center at the University of Texas at Austin. Surgical procedures were performed on animals anesthetized with ether. Rats of the AO strain were used because these animals often have a second nerve supplying the soleus muscle in addition to the soleus nerve. This "aberrant" nerve, derived from the plantar branch of the tibial nerve, is encountered in $>50 \%$ of soleus muscles in the AO strain but is seen only infrequently in other strains of rats (Thompson and Jansen, 1977). Motor units in the aberrant nerve do not differ from motor units in the soleus nerve in their physiological properties, and soleus muscles in rats with an aberrant nerve are innervated by the same number of motor units as in rats with no aberrant nerve (Thompson and Jansen, 1977). Muscle fibers innervated by axons in the two nerves intermingle throughout the muscle. Partial denervation of the soleus muscle in AO rats is easily accomplished by resection of the lateral gastrocnemius-soleus (LG-S) nerve, leaving the aberrant nerve intact. Resection of the LG-S nerve poses no danger of inadvertent injury to either the aberrant nerve or the soleus muscle.

\section{Surgical procedures}

Partial denervation. LG-S nerve resection was performed unilaterally in AO rats on postnatal day 14 (P14) or between postnatal days 25 and 30 (P25-30). By P14, motor units have reached their adult size (Brown et al., 1976). At P25-30, neuromuscular synapses are more fully mature, yet soleus muscles are not too large to prevent in vitro studies of synaptic function. The response of terminal Schwann cells to denervation differs dramatically between these two ages, with extensive terminal Schwann cell death after denervation on P14 but not P25-30 (Trachtenberg and Thompson, 1996). After exposure of the LG-S nerve in the popliteal fossa at the lateral head of the gastrocnemius muscle, a 3-5 mm segment of nerve was removed. The incision was closed using 6-0 silk suture. Survival time after partial denervation ranged from 1-3 d (for morphological and physiological assessment of remaining motor terminals) to 2-3 months (for physiological determination of motor unit size). For long survival times, the proximal nerve stump was ligated with $6-0$ surgical silk to prevent reinnervation by axons in the LG-S nerve.

Muscle removal. After the specified survival time, partially denervated soleus muscles and their nerves, including the sciatic nerve, were dissected into oxygenated Ringer's solution (in mM: $137 \mathrm{NaCl}, 4 \mathrm{KCl}, 1$ $\mathrm{MgCl}_{2} \cdot 6 \mathrm{H}_{2} \mathrm{O}, 1 \mathrm{KH}_{2} \mathrm{PO}_{4}, 12 \mathrm{NaHCO}_{3}, 2 \mathrm{CaCl}_{2} \cdot 2 \mathrm{H}_{2} \mathrm{O}, 11$ D-glucose; Liley, 1956). Muscles not innervated by an aberrant nerve (and therefore fully denervated by the LG-S nerve resection) were discarded. For experiments in which individual motor units were isolated, the nerve supply was dissected to include the L4 and L5 ventral roots, which contain the axons of all soleus motoneurons (Close, 1967). The contralateral, normally innervated soleus muscle from each animal was used as an internal control in experiments involving short survival times.

\section{Physiology}

Soleus muscles and nerves were continuously superfused in a bath of oxygenated Ringer's solution at room temperature. Each muscle was anchored to a Sylgard-coated dish by an insect pin through its proximal tendon and the head of the fibula. The distal tendon was attached to a force transducer (Harvard Apparatus, Holliston, MA; 60-2996; $40 \mathrm{mV}$ / gm; range, 0-50 gm; or Cambridge Technology, Cambridge, MA; 400A; $80 \mathrm{mV} / \mathrm{gm}$; range, $0-25 \mathrm{gm}$ ) for isometric tension measurements. Nerves were stimulated electrically through suction electrodes, or muscles were stimulated directly by current passed between two platinum plates positioned on either side of the muscle. At the beginning of each experiment, electrical stimulation of the soleus nerve distal to the resection site verified that no axons had regenerated to the muscle. After determining the muscle length at which maximum twitch tension was evoked by supramaximal stimulation of the nerve with pulses $0.2 \mathrm{msec}$ in duration, motor unit number was estimated by counting increments in twitch tension upon graded stimulation of the nerve. In some experiments, individual motor units were isolated by teasing the ventral roots into fine filaments until stimulation of a nerve filament resulted in an all-ornothing twitch of constant amplitude (Close, 1967; Brown et al., 1976; Brown and Ironton, 1978). Data were collected and analyzed using a MacLab analog-to-digital converter and Macintosh computer.

Motor unit expansion. To determine the extent of motor unit expansion after partial denervation on P14, motor unit number and muscle fiber number were counted 2-3 months after resection and ligation of the LG-S nerve, sufficient time for the remaining soleus motor units to fully expand (Thompson and Jansen, 1977). Lack of reinnervation through the soleus nerve was verified, then motor unit number and relative sizes were estimated by graded stimulation of the aberrant nerve. To avoid constraints on motor unit expansion (Thompson and Jansen, 1977), muscles innervated by more than six units were excluded: if too many motor units were present, there would be a ceiling on the number of muscle fibers each could innervate, simply because of the limited number of muscle fibers. Motor unit number also was estimated in normal soleus muscles innervated through both soleus and aberrant nerves. Muscles were frozen in isopentane (2-methylbutane) cooled to $-60^{\circ} \mathrm{C}$ with liquid nitrogen and sectioned in a cryostat at the level of the endplate band (verified by $\alpha$-bungarotoxin staining), a level containing profiles of all fibers in the muscle (Close, 1964). Muscle cross-sections $10 \mu \mathrm{m}$ thick were stained for myosin ATPase activity after an alkaline preincubation (modified from Guth and Samaha, 1970). Stained sections were rinsed in distilled $\mathrm{H}_{2} \mathrm{O}$, dehydrated, cleared, and coverslipped in Permount. Muscle fibers were counted, and motor unit size was calculated based on the percentage of total twitch tension each unit produced. For example, if stimulation of a motor unit produced $25 \%$ of the total force produced by a muscle, it was assumed to innervate $25 \%$ of the muscle fibers. Motor units and muscle fibers were counted in eight muscles partially denervated on P14 and in four normal soleus muscles taken from animals not subjected to any previous surgery.

Intracellular physiology. Three days after partial denervation on P14, intracellular recordings were made from muscle fibers in the endplate band using glass microelectrodes filled with $3 \mathrm{~m}$ potassium acetate $(50-$ $100 \mathrm{M} \Omega$ resistance), and a high input impedance microelectrode amplifier (WPI KS-700). The nerve was stimulated at $100 \mathrm{~Hz}$ for $220 \mathrm{msec}$, and synaptic potentials were recorded. Because muscle contractions were weak (see Results), impalements could usually be maintained without any pharmacological manipulation to prevent muscle contractions, and intracellular recordings therefore were made in normal Ringer's solution.

Synaptic safety factor. The neuromuscular junction normally has a high safety factor; i.e., much more neurotransmitter is released and binds to acetylcholine receptors (AChRs) than is necessary to bring the postsynaptic muscle fiber to threshold. This is evidenced by the fact that $80-90 \%$ of AChRs must be blocked before evoked contraction is prevented (Lingle and Steinbach, 1988). Two approaches were used to assess synaptic safety factor in muscles partially denervated for $3 \mathrm{~d}$. In the first set of experiments, the AChR antagonist curare was bath-applied at steps of increasing concentrations (ranging from $1 \times 10^{-7}$ to $6.5 \times 10^{-7}$ $\mathrm{gm} / \mathrm{ml}$ ). Twitch tension stabilized within $30 \mathrm{~min}$ of curare application, at which time the nerve was stimulated and twitch tension was recorded as an average of 3 trials separated by about $30 \mathrm{sec}$. In this manner, we determined the concentration of curare (to within $0.5 \times 10^{-7} \mathrm{gm} / \mathrm{ml}$ ) necessary to completely block evoked muscle contraction $(n=5$ at P14; $n=6$ at P25-30). Synaptic safety factor also was tested with curare in an additional group of soleus muscles from normal (i.e., no surgery) P17 and P26-29 animals ( $n=3$ at each age). For each of these experiments, a P17 muscle was paired with an older muscle in the same bath. In a second set of experiments designed to assess synaptic safety factor after partial denervation, calcium concentration in the bath was decreased in the following steps: 2 (normal), 1.6, 1.2, 0.8, and $0.4 \mathrm{~mm}$ (Jordan et al., 1992). Lowering extracellular calcium levels reduces the driving force on calcium, resulting in less calcium influx and therefore less neurotransmitter release in response to each action potential. Evoked twitch tension was recorded as an average of three trials after $30 \mathrm{~min}$ at each concentration $(n=4$ at each age). Experiments were conducted simultaneously on a partially denervated soleus muscle and its contralateral control in the same bath so that both were exposed to exactly the same concentration of 
curare or calcium. At the end of each experiment, muscles were processed for immunohistochemical labeling of neuromuscular junctions as described below.

\section{Morphology of the neuromuscular junction}

Terminal morphology and sprouting. Muscles were fixed in $4 \%$ buffered paraformaldehyde (10-30 min), permeabilized in absolute $\mathrm{MeOH}$ cooled to $-20^{\circ} \mathrm{C}(5-10 \mathrm{~min})$, blocked for $30 \mathrm{~min}(0.3 \%$ Triton $\mathrm{X}-100$, $0.2 \%$ BSA, $0.1 \%$ sodium azide in PBS), and incubated overnight in the primary antibodies of interest, diluted in blocker. The following primary antibodies were used: a polyclonal antibody to S100 to visualize Schwann cells (1:400; Dako, Glostrup, Denmark; Z0311), a monoclonal antibody to neurofilament (2H3) to visualize axons (1:200; Developmental Studies Hybridoma Bank, University of Iowa, Department of Biological Sciences, Iowa City, IA), a monoclonal antibody to synaptophysin (1:400; Sigma, St. Louis, MO; S5768) or the synaptic vesicle protein SV2 (1:400; Developmental Studies Hybridoma Bank) to visualize nerve terminals, a monoclonal antibody to protein zero (P07) to visualize myelin sheaths (1:200; courtesy of Dr. J. J. Archelos, University of Wurzburg, Wurzburg, Germany), and a monoclonal antibody (G3G4) to 5-bromo-2'deoxyuridine (BrdU) to visualize mitotically active cells (1:5; Developmental Studies Hybridoma Bank). When the protein zero antibody was used, paraformaldehyde fixation was omitted; when G3G4 was used, muscles were incubated in $2 \mathrm{~N} \mathrm{HCl}$ and $0.3 \%$ Triton for $30 \mathrm{~min}$ before blocking. Primary antibodies were visualized with the following fluorochromeconjugated secondary antibodies: fluorescein isothiocyanate-conjugated sheep anti-mouse (1:100; Sigma; F2266) and tetramethylrhodamine isothiocyanate-conjugated goat anti-rabbit (1:400; Cappel, West Chester, PA; 55671) or Cy5-conjugated goat anti-rabbit (1:100; Jackson ImmunoResearch, West Grove, PA). AChRs were visualized using rhodamine- or Cy5-conjugated $\alpha$-bungarotoxin. After staining, a thin layer of muscle fibers was dissected off each side of the muscle and mounted in fluorescence mounting medium $(0.1 \mathrm{M}$ ethanolamine, $0.01 \mathrm{M} p$-phenylenediamine in $90 \%$ glycerol, $\mathrm{pH}$ 9.5; modified from Johnson and Nogueira Araujo, 1981). Analyses were conducted using a $63 \times, 1.32$ numerical aperture (NA) or a $100 \times, 1.30$ NA objective, an integrated, cooled CCD camera (Carl Zeiss, Thornwood, NY), and NIH Image software (available on the Internet at nih.gov).

Hoffman (1950) described two types of motoneuronal sprouts: those that originate from the terminal (terminal sprouts) and those that originate from nodes of Ranvier (nodal sprouts). In the present study, terminal sprouts were defined as nerve processes extending from a terminal beyond the boundary of AChR label, a liberal definition that included even the shortest of sprouts (as short as $1 \mu \mathrm{m}$ ). Nodal sprouts were identified as thin axonal branches that reached a synaptic site (i.e., an AChR plaque) but did not originate from a terminal branch. These nodal sprouts were associated with Schwann cell processes and may have reached the denervated site by growing along the endoneurial tube that remained after axonal degeneration or by following new Schwann cell processes extending from the intramuscular nerve. Each endplate was first categorized as being (1) innervated by an axon ("axon-derived"), (2) fully denervated (i.e., not contacted by a neuronal process of any sort), (3) denervated but contacted by a terminal sprout, or (4) denervated but contacted by a nodal sprout. Axon-derived terminals were further divided based on whether they had extended terminal sprouts.

Schwann cell mitosis. To determine whether partial denervation on P14 caused mitotic activity in terminal Schwann cells, cells actively synthesizing DNA were labeled with BrdU (Calbiochem, La Jolla, CA; 203806). Soleus muscles $(n=3)$ were partially denervated on P14, and animals were given intraperitoneal BrdU injections $(0.1 \mathrm{mg} / \mathrm{gm}$ body weight, dissolved in $0.9 \% \mathrm{NaCl}$ containing $0.007 \mathrm{~N} \mathrm{NaOH}$; Love and Thompson, 1998) twice daily for $3 \mathrm{~d}$ (P15-17). Thirty minutes after a final BrdU injection on P18 (4 d after partial denervation), muscles were removed and processed for immunohistochemical labeling using antibodies to BrdU, neurofilament, and S100 (see above).

\section{Statistical analyses}

Statistical analyses were performed using StatView (SAS Institute Inc., Cary, NC), typically as two-way ANOVAs, with age as a between-group factor (P14 vs P25-30) and partial denervation as a within-group factor (partially denervated muscle vs contralateral control muscle). Significant two-way interactions were followed by hypothesis-driven post hoc comparisons using Fisher's PLSD. Data are presented as mean \pm SEM.

\section{RESULTS}

Partial denervation of adult muscle results in an expansion of approximately fourfold to fivefold in motor unit size (Thompson and Jansen, 1977; Brown and Ironton, 1978). Such an expansion does not occur after partial denervation shortly after birth (Brown et al., 1976; Thompson and Jansen, 1977; Betz et al., 1980), when motoneurons have not completed synapse elimination and therefore already have an enlarged terminal arbor. By P14, synapse elimination is essentially complete, and each motoneuron innervates the same number of muscle fibers as in adulthood (Brown et al., 1976). In addition, after complete denervation of muscles at this age, most terminal Schwann cells die (Trachtenberg and Thompson, 1996). Because these cells appear to play a critical role in inducing and guiding terminal sprouts to reinnervate denervated sites after partial denervation of mature muscles (Son and Thompson, 1995b), we were interested in the behavior of motor terminals after partial denervation at an age at which terminal Schwann cells at denervated sites die. Finally, previous studies of motor unit expansion after partial denervation considered only relatively long survival times (weeks to months), and there is a dearth of information about the anatomy and physiology of nerve terminals in the time shortly after partial denervation. We therefore examined morphological and functional characteristics of the neuromuscular junction shortly after partial denervation.

\section{P14 motoneurons show only limited increases in motor unit size after partial denervation}

The soleus muscle was partially denervated on P14, and 2-3 months later motor units and muscle fibers were counted to estimate motor unit size. Normal adult soleus muscles $(n=4)$ contained $3365 \pm 115$ fibers and were innervated by $31 \pm 0.7$ motoneurons. Thus, each soleus motoneuron would be expected to innervate 109 fibers, on average. These numbers are consistent with previous estimates (Close, 1967; Brown et al., 1976; Kugelberg, 1976; Thompson and Jansen, 1977). Partial denervation on P14 resulted in motor units that were larger than those seen after partial denervation earlier in development, on P1-5 (Fig. 1). However, after partial denervation on P14, motor unit expansion was less than that seen after partial denervation in adulthood. The mean size of 39 motor units in eight muscles partially denervated on P14 was 355 fibers, compared with 524 fibers in muscles partially denervated in adulthood (Thompson and Jansen, 1977). Some units in muscles partially denervated in adulthood were larger than any seen after partial denervation at younger ages (Fig. 1, Adult, dark bars), and some units in muscles partially denervated on P14 were smaller than any found after partial denervation in adulthood (Fig. 1, P14, dark bars). Thus, even though motor units had achieved their adult size by P14, they still were deficient in expanding to reinnervate denervated fibers.

\section{P14 motoneurons extend nodal sprouts but not terminal sprouts in response to partial denervation}

As a first step toward understanding why young motoneurons do not expand to the same extent as their adult counterparts after partial denervation, we looked for evidence of the initial sprouting response $3 \mathrm{~d}$ after partial denervation. Partial denervation of P25-30 muscles resulted in terminal sprouting by almost all terminals 3 d later (Fig. $2 A, B$ ), but in muscles partially denervated on $\mathrm{P} 14$ there was no increase in the percentage of terminals with sprouts compared with normally innervated, contralateral 


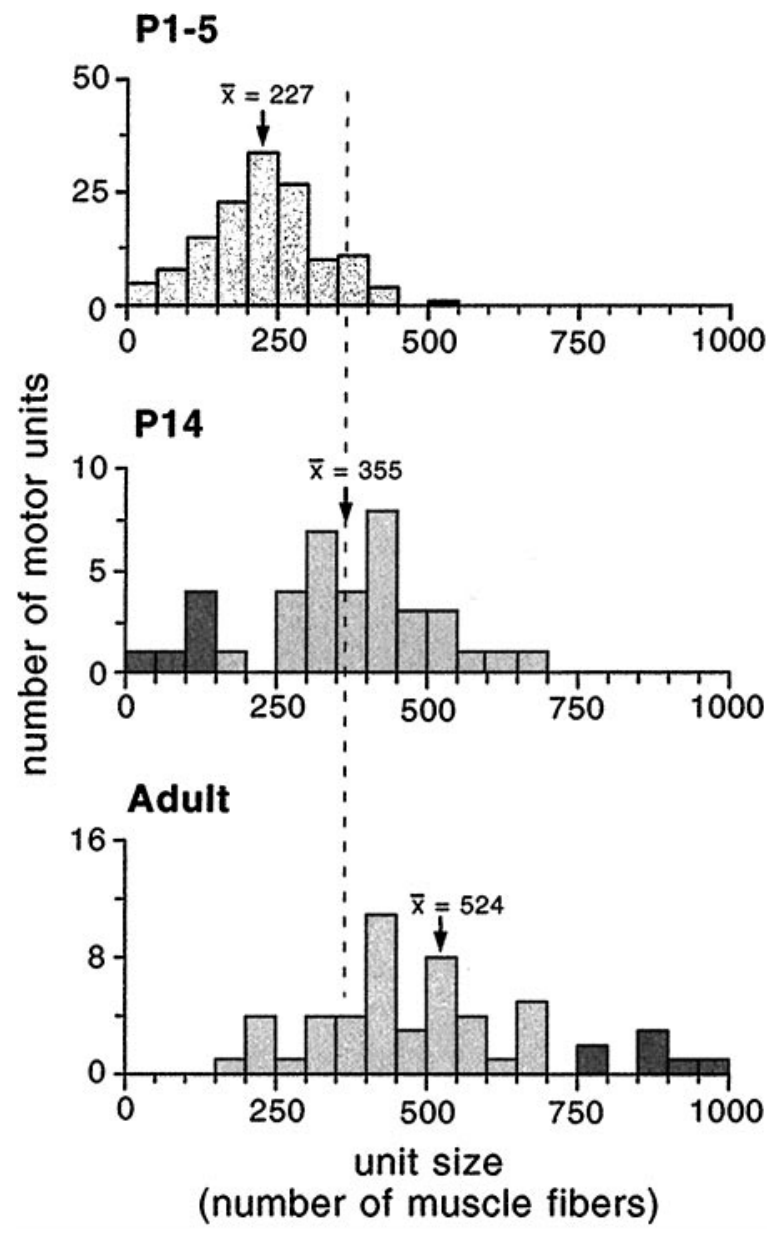

Figure 1. Motor unit expansion is impaired after partial denervation on P14, at the end of synapse elimination. Soleus muscles were partially denervated at the indicated age, and motor unit size was determined 2-3 months later (see Materials and Methods). After partial denervation in adulthood (bottom), motor units expand from their normal size of 100 150 fibers to an average of 524 fibers. After partial denervation on P1-5 (top), average motor unit size is only 227 fibers. Normal motor units at P1-5 are $\sim 700$ fibers large; therefore some developmental synapse elimination appears to continue even after partial denervation at this age. After partial denervation on P14 (middle), motor units expanded to an average of 355 fibers (dotted line), smaller than in adult muscles. After partial denervation on P14, some units (middle, dark bars) were smaller than any seen after partial denervation in adulthood, whereas after partial denervation in adulthood, some units (bottom, dark bars) are larger than any seen after partial denervation in development. Data on partial denervations on P1-5 and in adults were taken from Thompson and Jansen (1977).

controls (Fig. 2C). The mean number of sprouts per terminal was also higher in muscles partially denervated on P25-30 than in any other group (Fig. 2D). The only effect of P14 partial denervation on terminal sprouts was an increase in sprout length compared with contralateral controls, and terminal sprouts were even longer in muscles partially denervated on P25-30 (Fig. 2E). Importantly, denervated endplates were more likely to be contacted by terminal sprouts in older muscles than in muscles partially denervated on P14 (Fig. 3A-C). Three days after partial denervation on P25-30, $6.1 \%$ of endplates had been contacted by a terminal sprout. This is consistent with the finding of Son and Thompson (1995b) that 3 d after partial denervation, reactive Schwann cell processes at $\sim 7 \%$ of denervated endplates had made contact with adjacent, innervated endplates. Differences in terminal sprouting were not attributable to differences in the extent of denervation: there were $5.8 \pm 0.84$ motor units still innervating the partially denervated P14 muscles and $6.1 \pm 0.86$ units still innervating the partially denervated $\mathrm{P} 25-30$ muscles $(p>0.70)$. In addition, Brown and colleagues (1980) found no relationship between the amount of nodal or terminal sprouting by soleus motoneurons and the extent of partial denervation.

In contrast to terminal sprouting, nodal sprouting by immature motoneurons did not appear to be impaired (Fig. 3D,E). Although difficult to quantify, there looked to be extensive growth of nodal sprouts in muscles partially denervated on P14. One indication of such growth was our finding in one muscle of sprouts that had started to grow back up the distal stump of the soleus nerve, as has been described previously (Thompson, 1978). We did not, however, look for this in a systematic manner. Based on the percentage of endplates contacted by nodal sprouts, nodal sprouting after partial denervation was apparently more robust in younger muscles $(16.9 \pm 4.02 \%)$ than in more mature muscles $(6.1 \pm 1.47 \% ; p<0.05)$. It is important to note, however, that axons in the process of withdrawing from contact with the muscle fiber might have a morphology (Gan and Lichtman, 1998) similar to those defined herein as nodal sprouts. In normal P14 muscles labeled with our immunohistochemical technique $(n=4), 10.6 \pm$ $1.59 \%$ of endplates were still contacted both by an axon and by a second, fine process, not yet withdrawn. If these were maintained in partially denervated muscles, then the actual percentage of endplates contacted by nodal sprouts would be lower than $16.9 \%$, closer to that seen in older muscles after partial denervation. Although we may, therefore, have overestimated the extent of nodal sprouting in neonatal muscles, there is no evidence for an impairment of nodal sprouting after partial denervation on P14 relative to that seen after partial denervation on $\mathrm{P} 25-30$.

\section{Schwann cells react to partial denervation in an age-dependent manner}

Terminal Schwann cells die after full denervation of neonatal muscles (Trachtenberg and Thompson, 1996). To determine whether Schwann cell death also results from partial denervation, we labeled Schwann cells either 1 or $3 \mathrm{~d}$ after partial denervation on P14 with an antibody to S100, in combination with fluorescent labeling of nerve processes and AChRs. Partial denervation on P14 resulted in an extensive loss of Schwann cells at denervated but not innervated endplates. One day after partial denervation on P14 ( $n=2$ muscles), many denervated endplates were found to have cells with S100-positive cytoplasm condensed around an S100-negative nucleus and/or were fragmented into small, S100positive pieces, features characteristic of apoptosis in these cells (Trachtenberg and Thompson, 1996). Apoptotic Schwann cells were not seen over innervated endplates. Three days after partial denervation on P14 ( $n=5$ muscles), most $(67.5 \pm 8.68 \%)$ denervated endplates were completely devoid of Schwann cell coverage. Of the denervated endplates that still had Schwann cells present, almost all (44 of 45) were only partially covered by Schwann cells and their processes. The Schwann cells that remained at denervated sites extended processes away from the endplate in only $42 \%$ of cases. In contrast, in muscles partially denervated on P25-30 $(n=4),<1 \%$ were completely devoid of Schwann cells $3 \mathrm{~d}$ after partial denervation, and $75 \%$ were fully covered by Schwann cells and their processes. In these older muscles, Schwann cells at denervated sites extended processes away from the endplate in $91 \%$ of cases. Thus, after partial denervation on P14, most denervated endplates had lost all of 

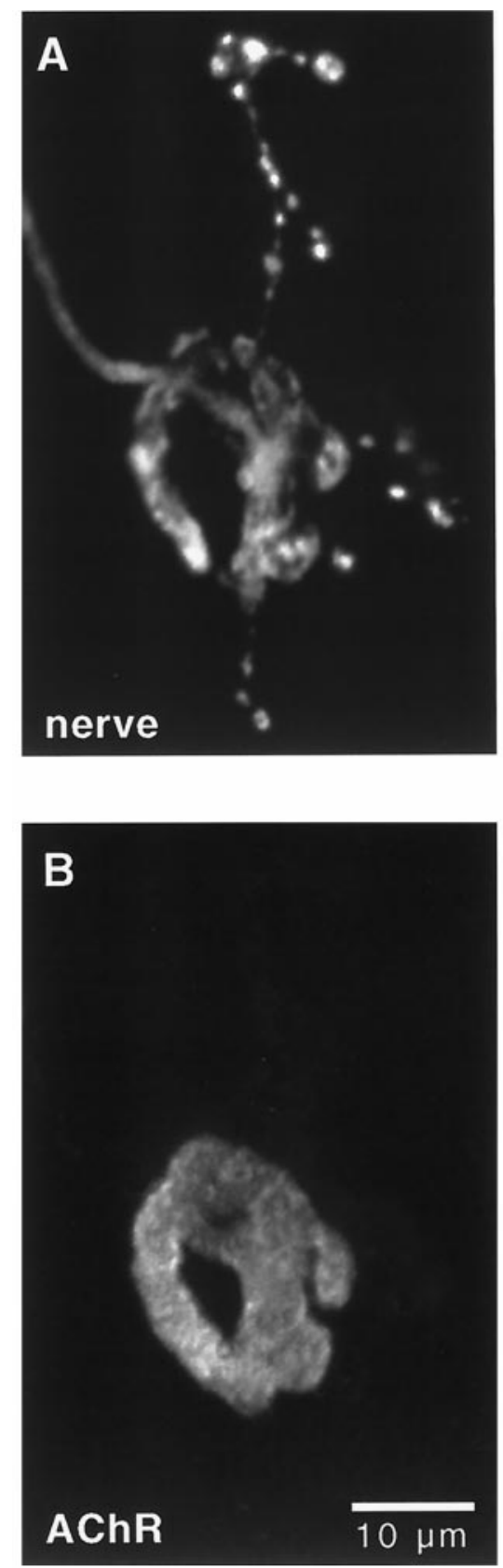
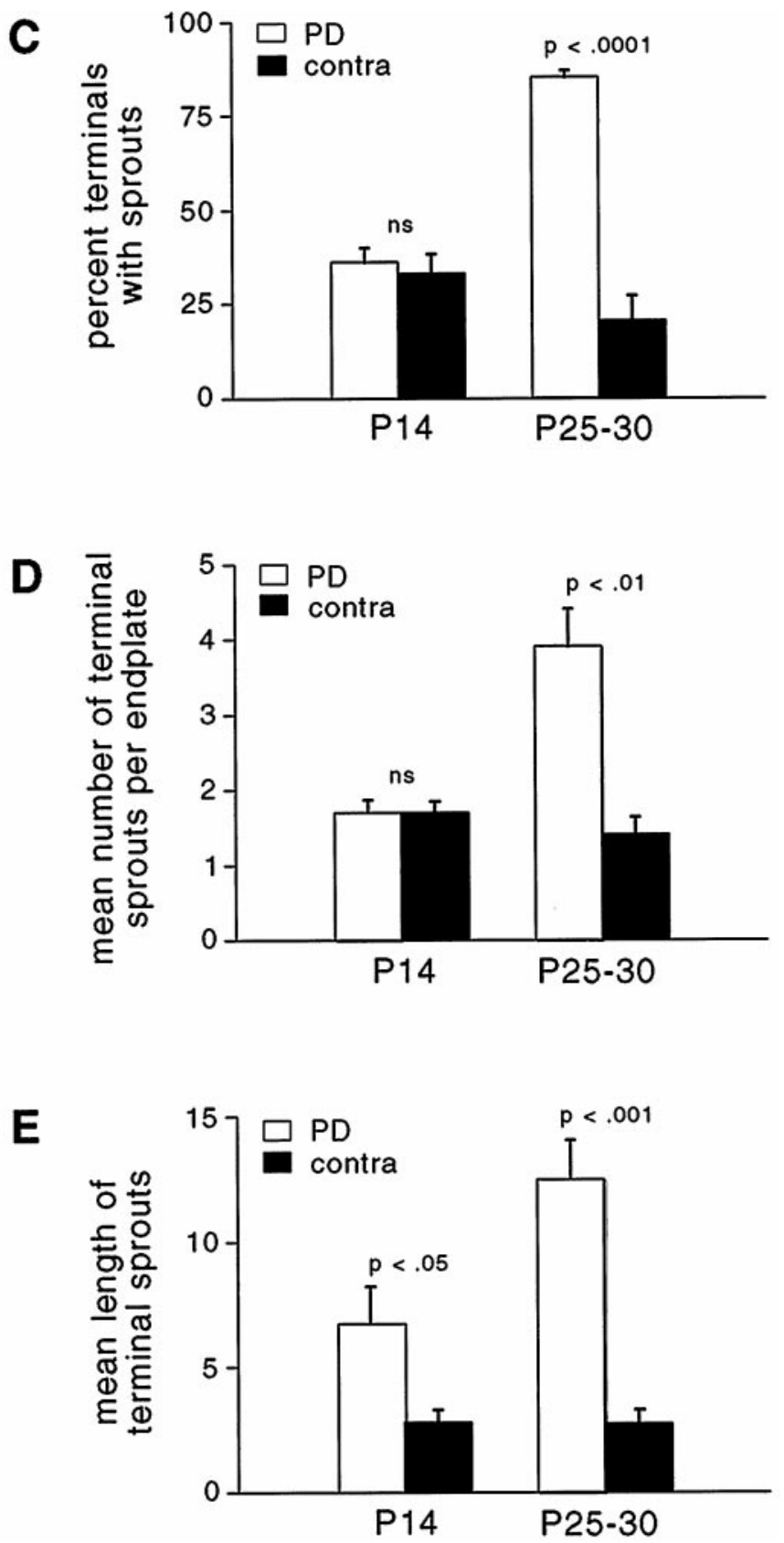

Figure 2. Terminal sprouting is robust in more mature muscles (P25-30) but deficient in younger muscles (P14) $3 \mathrm{~d}$ after partial denervation $(P D)$. $A$, $B$, Confocal photomicrographs of an endplate $3 \mathrm{~d}$ after partial denervation on P35. Nerve processes $(A)$ were labeled with antibodies to neurofilament and synaptophysin, and AChRs $(B)$ were labeled with $\alpha$-bungarotoxin. Terminal sprouts can be seen extending well beyond the AChR plaque. $C$, The percentage of terminals with sprouts is much higher in muscles partially denervated on P25-30 than in younger muscles or in contralateral control muscles (contra). Two-way interaction, $p<0.0001 ; n=8$ at P14; $n=7$ at P25-30. D, The mean number of terminal sprouts per endplate (excluding endplates with no sprouts) is higher in mature muscles than in neonatal muscles or contralateral controls. Two-way interaction, $p<0.01 ; n=5$ at P14; $n=4$ at P25-30. E, Terminal sprouts are longer in partially denervated muscles than in contralateral controls and longer in older muscles than in immature muscles after partial denervation. Two-way interaction, $p<0.05 ; n=5$ at P14; $n=4$ at P25-30.

their terminal Schwann cells; the rest appeared to have lost a portion of their Schwann cells, and the Schwann cells that remained were less likely to extend processes than their counterparts in more mature muscles.

Consistent with previous work (Son and Thompson, 1995a,b), Schwann cell processes accompanied almost all terminal and nodal sprouts. Although we did see instances $(\sim 10 \%)$ of terminal sprouts in which Schwann cell coverage did not extend fully to the tip of the sprout, these were extremely subtle and were indepen- dent of partial denervation and of the age of the animal. Such cases may not have been seen by Son and Thompson (1995a,b) because they stained nerve processes with antibodies only to neurofilament and not to synaptophysin. We also observed a few examples of nodal sprouts that were not fully covered by Schwann cells 3 d after partial denervation on P14 but not after partial denervation on P25-30 (Fig. 4). These sprouts usually had a punctate appearance, morphology not typical of nodal sprouts. Although these data are based on static images and consist of only 
A
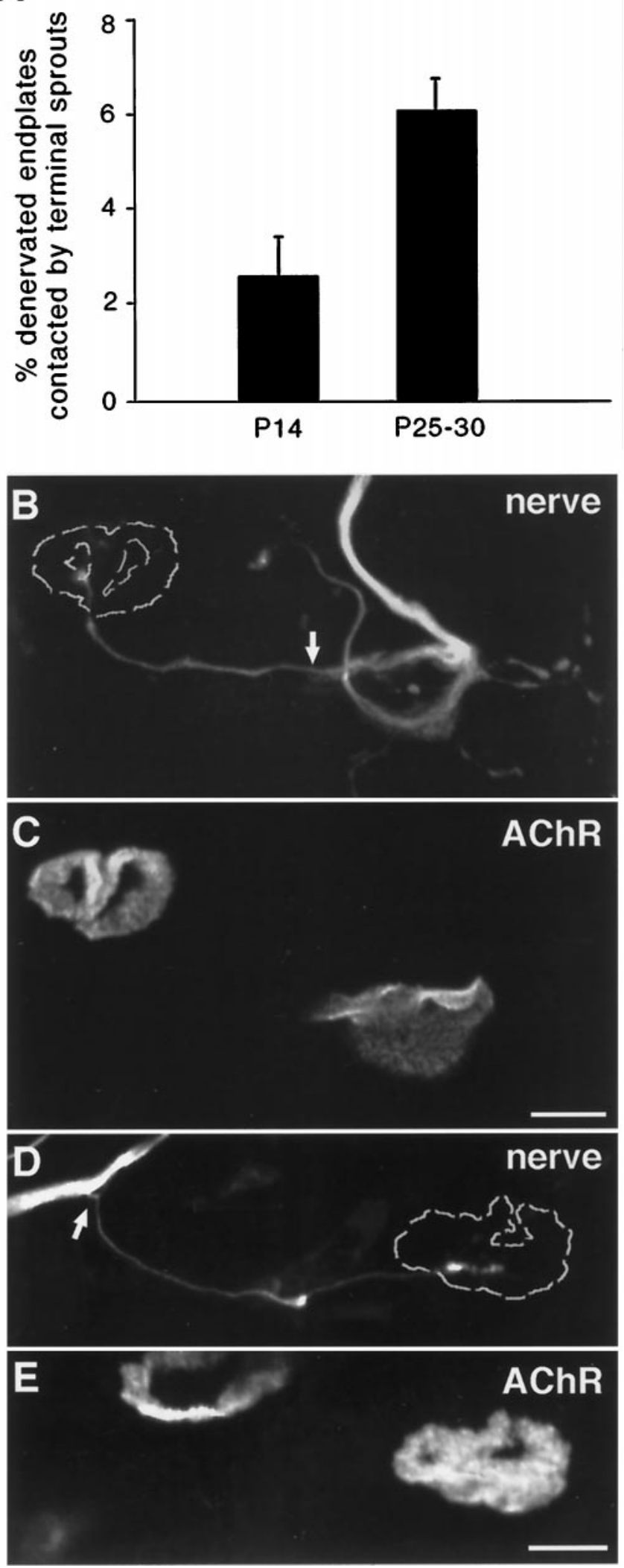

Figure 3. Terminal sprouts are less likely to contact denervated endplates in muscles partially denervated on P14 than in muscles partially denervated on P25-30. A, The percentage of denervated endplates contacted by terminal sprouts was determined $3 \mathrm{~d}$ after partial denervation by labeling nerve terminals, axons, and AChRs for fluorescence microscopy. One-way ANOVA, $p<0.01 ; n=8$ at P14; $n=7$ at P25-30.
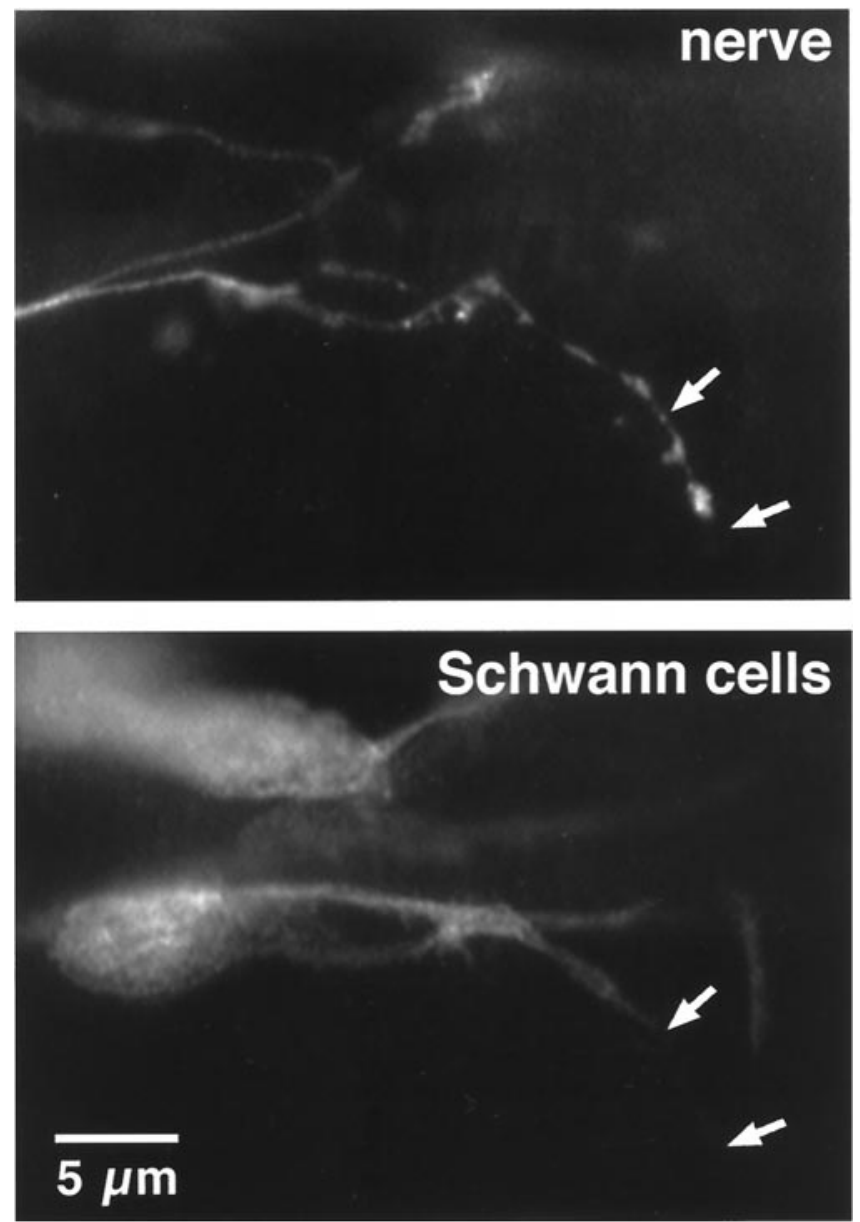

Figure 4. In muscles partially denervated on P14, nodal sprouts were occasionally found that were not fully covered by Schwann cell processes. Three days after partial denervation on P14, this muscle was processed immunohistochemically with antibodies to neurofilament, synaptophysin, and SV2 to label nerve processes (top panel) and antibodies to S100 to label Schwann cells (bottom panel). In this photomontage, a nodal sprout enters the field of view from the left and branches several times. Arrows indicate the distal end of one branch of this sprout that is not accompanied by a Schwann cell process. Note the spotty appearance of this branch of the sprout. No endplate was seen in the vicinity of this branch (data not shown).

a few observations, it is tempting to speculate that these cases of varicose sprouts not fully covered by Schwann cells, as well as the terminal sprouts not fully covered, represent dynamic interrelationships between Schwann cell and nerve process extension and retraction. Such a dynamic relationship is suggested for terminal sprouts by preliminary observations that many of the short sprouts present $3 \mathrm{~d}$ after partial denervation have disappeared a few days later (F. M. Love and W. J. Thompson, unpublished observations).

$\leftarrow$

$\overline{B-E \text {, Confocal photomicrographs of a terminal sprout }(B, C) \text { and a nodal }}$ sprout $(D, E)$ in contact with denervated endplates. Nerve processes $(B$, $D$ ) were labeled with antibodies to neurofilament and synaptophysin, and AChRs $(C, E)$ were labeled with $\alpha$-bungarotoxin. In both examples, the denervated endplate site is outlined, and an arrow shows where the sprout branches from a terminal $(B)$ or from an axon $(D)$. These photomicrographs were taken $3 \mathrm{~d}$ after partial denervation on $\mathrm{P} 30(B, C)$ or P14 $(D$, $E)$. At this time, there is little arborization by sprouts in contact with denervated endplates. Scale bars, $10 \mu \mathrm{m}$. 
After partial denervation of soleus muscles at 5 weeks of age, Love and Thompson (1998) found BrdU-positive Schwann cells at $27 \%$ of innervated endplates. In these muscles, BrdU-positive Schwann cells are most common at innervated endplates that have been contacted by reactive Schwann cell processes from nearby denervated sites. Following the same protocol, we found BrdU-positive Schwann cells at only $7.1 \pm 0.60 \%$ of innervated endplate sites after partial denervation on P14 (10 of 150 endplates in three muscles). Thus, after partial denervation on P14, in the absence of Schwann cell processes from denervated endplates, Schwann cells at innervated endplates are less likely to become mitotic. This is consistent with the idea that Schwann cell processes growing from denervated endplates play a role in inducing Schwann cell mitosis at innervated endplates.

\section{Motor units produce less tension shortly after partial denervation on P14}

Schwann cells made reactive by denervation or (in neonates) by application of glial growth factor can alter synaptic morphology and function (Trachtenberg and Thompson, 1997). We therefore looked for evidence of functional synaptic changes after partial denervation by studying the ability of the nerve to evoke muscle contraction. Soleus muscles were partially denervated on P14 or P25-30, and 3 d later the muscle tension evoked by stimulation of the sciatic nerve was recorded. Repetitive stimulation revealed an inability of muscles partially denervated on P14 to maintain tension throughout $1500 \mathrm{msec}$ of stimulation (Fig. $5 \mathrm{~A}$ ), even at a stimulation frequency as low as $2 \mathrm{~Hz}$. The fifth stimulus delivered at $2 \mathrm{~Hz}$ produced $75.6 \pm 3.85 \%$ as much tension as the first stimulus, whereas in muscles partially denervated on P25-30, the fifth stimulus produced $93.9 \pm 1.00 \%$ as much tension as the first. When muscles partially denervated on P14 were stimulated by direct activation of the muscle fibers at $100 \mathrm{~Hz}$ for $1500 \mathrm{msec}$, there was no decline in tension (i.e., fade). These observations suggest a deficiency in synaptic transmission rather than in the ability of the muscle to generate or maintain tension.

Differences between young and older muscles could not be accounted for by differences in the extent of partial denervation. In these experiments, partially denervated P14 muscles were innervated by $6.4 \pm 0.71$ (range, 3-9) motor units, and partially denervated P25-30 muscles were innervated by $8.3 \pm 0.90$ (range, $5-13)$ units $(p>0.1)$. Within this range of motor unit number, there was no clear relationship between the number of units innervating a partially denervated muscle and the severity of the effects (Fig. $5 B$ ) either at P14 $\left(r^{2}=0.023 ; p=0.70\right)$ or at P25-30 $\left(r^{2}=0.285 ; p=0.11\right)$.

We confirmed these deficits in synaptic transmission by examining single motor units. Soleus muscles partially denervated on P14 ( $n=4$ animals) were dissected 2-3 d later with their contralateral control muscles so that motor units could be isolated from the ventral roots and stimulated individually (3-11 units sampled per muscle). Partially denervated muscles in this group remained innervated by three to seven motor units. The amplitude of the twitches evoked by stimulating these units tended to be smaller than those evoked in contralateral control muscles, although this did not reach statistical significance (Table 1). However, the maximum tetanic forces produced by single motor units were, on average, less than half the size of those in the contralateral control muscle ( $p<0.05$; Table 1 , Fig. $6 A$ ). Moreover, as was seen after whole nerve stimulation, isolated units in muscles partially denervated on P14 failed to maintain peak
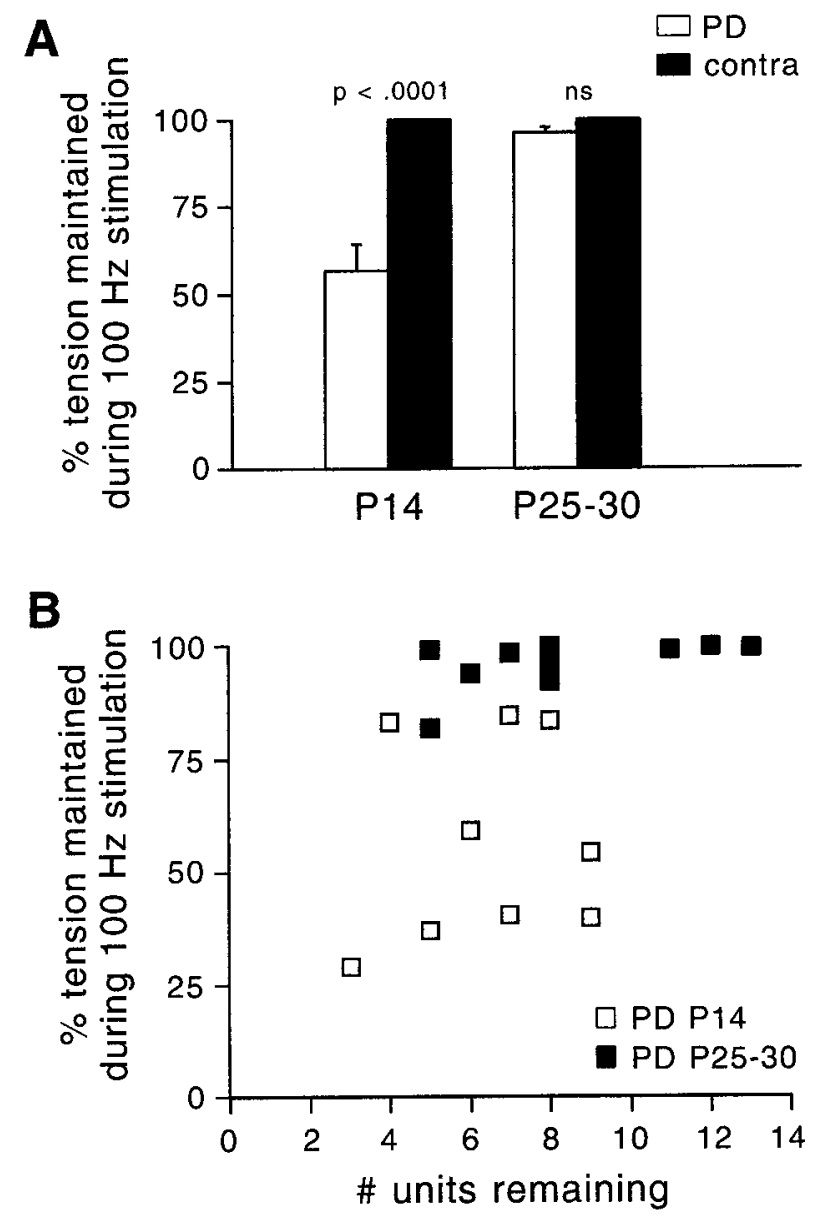

Figure 5. Muscles partially denervated on P14 do not maintain tension during high-frequency nerve stimulation. $A$, Control muscles (contra) and muscles partially denervated $(P D)$ on P25-30 maintained 95-100\% tension during the $1500 \mathrm{msec}$ of nerve stimulation at $100 \mathrm{~Hz}$, whereas tension produced by muscles partially denervated on P14 dropped by almost half. Two-way interaction, $p<0.0001 ; n=9$ at P14; $n=10$ at P25-30. $B$, This fade during high-frequency stimulation was independent of the number of units still innervating the muscle within the range of units considered (3-13): P14, $r^{2}=0.023, p=0.70 ; \mathrm{P} 25-30, r^{2}=0.285, p=0.11$.

Table 1. Motor unit tension 3 d after partial denervation (PD) on P14

\begin{tabular}{lll} 
& PD & Contra \\
\hline Twitch tension $(\mathrm{gm})$ & $0.11 \pm 0.02$ & $0.18 \pm 0.01$ \\
Maximum tetanic tension $(\mathrm{gm})$ & $0.21 \pm 0.04^{*}$ & $0.52 \pm 0.04$ \\
$\begin{array}{l}\text { Tension maintained during } 100 \\
\text { Hz stimulation }(\%)\end{array}$ & $48.9 \pm 11.55^{*}$ & $98.7 \pm 0.51$ \\
\hline
\end{tabular}

$\overline{\text { Data are presented as mean } \pm \text { SEM, based on a sample size of four muscles per }}$ group, 3-11 units sampled per muscle.

* Significantly different from contralateral control units (Contra), $p<0.05$.

tension throughout a $1500 \mathrm{msec}$ train of stimuli at frequencies from 10 to $100 \mathrm{~Hz}$ (Fig. 6B). On average, tension at the end of $1500 \mathrm{msec}$ of $100 \mathrm{~Hz}$ stimulation of a motor unit was less than half of the peak tension (Table 1). Units from contralateral control muscles showed no such drop (Table 1). As evidenced by decreased tetanic tension and the failure to maintain tension during repetitive stimulation, partial denervation on P14 lessened the ability of the remaining motoneurons to evoke contraction in muscle fibers they innervated at the time of partial denervation. 


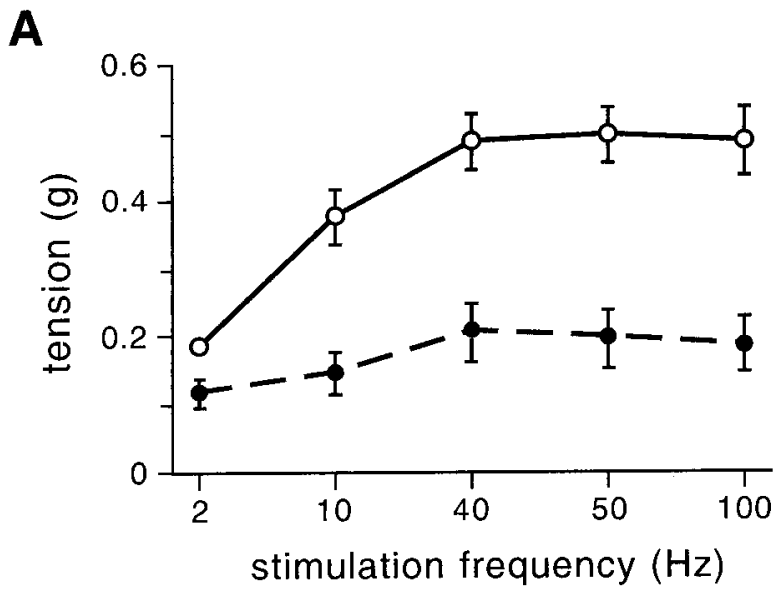

B

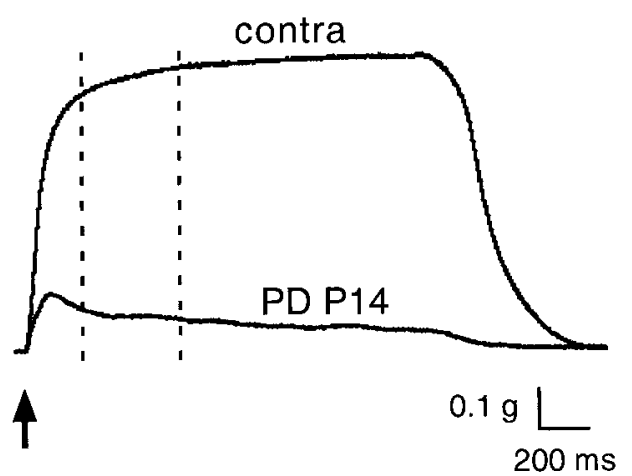

Figure 6. Motor units produce less tension $3 \mathrm{~d}$ after partial denervation on P14. $A$, Frequency-tension curves for motor units isolated from muscles partially denervated 3 d earlier on P14 (filled circles) and contralateral controls (open circles). Motor unit twitch tension $(2 \mathrm{~Hz}$ stimulation) is slightly lower in experimental muscles. Stimulation of motor units at higher frequencies reveals a more dramatic decrease in the ability to generate tension after partial denervation $(n=4$ animals). $B$, Stimulation at $100 \mathrm{~Hz}$ for $1500 \mathrm{msec}$ of a motor unit from a muscle partially denervated on P14 (PD P14) and its contralateral control muscle (contra). Stimulation of the unit in the partially denervated muscle produced less tension, and maximum tension was not maintained for the duration of the stimulus. The arrow indicates stimulus onset. The dashed lines mark 220 and $600 \mathrm{msec}$ after stimulus onset, intervals during which intracellular recording was used to examine branch point failure (see Results).

\section{Branch point failure cannot account for the decreased tetanic tension or the fade seen during repetitive stimulation after partial denervation on P14}

Extensive nodal sprouting might result in the failure of action potential conduction at axonal branch points, particularly during repetitive stimulation (Krnjevic and Miledi, 1957). If this were occurring, one would expect to see a frequency-dependent increase in failures to evoke an excitatory junctional potential (EJP) by nerve stimulation. We tested this by recording intracellularly in muscle fibers during $100 \mathrm{~Hz}$ stimulation of the nerve for 220 msec. Consistent with other evidence of weakened synapses, muscle responses to nerve stimulation $3 \mathrm{~d}$ after partial denervation on P14 were usually weak enough that electrode impalements could be maintained without any pharmacological manipulation to prevent muscle contraction. A total of 58 innervated muscle fibers were sampled in three muscles partially denervated $3 \mathrm{~d}$ earlier on P14 (13-26 fibers per muscle). Each muscle was inner-

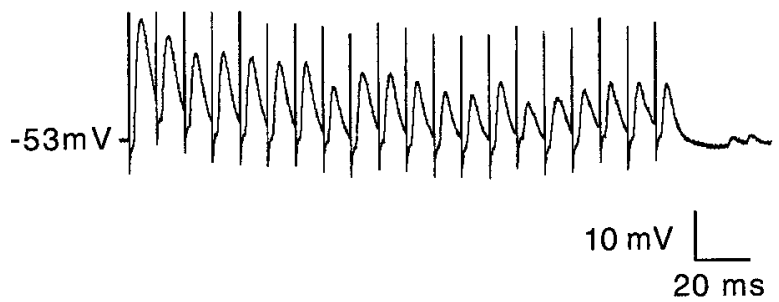

Figure 7. Conduction failure does not account for muscle tension deficits $3 \mathrm{~d}$ after partial denervation on P14. This intracellular muscle fiber recording was made in a muscle that had been partially denervated $3 \mathrm{~d}$ earlier on P14. EJPs were evoked by $100 \mathrm{~Hz}$ nerve stimulation. No failures to evoke an EJP were seen in this fiber, but EJPs were subthreshold, and their amplitude decreased during the $220 \mathrm{msec}$ stimulation.

vated by two to six motoneurons. After $220 \mathrm{msec}$ of $100 \mathrm{~Hz}$ stimulation (Fig. 6B, dashed line on left), units in contralateral muscles produced $0.42 \pm 0.037 \mathrm{gm}$ force and had not yet reached peak tension. In contrast, units in muscles partially denervated on P14 produced only $0.15 \pm 0.046$ gm force and were already losing tension. Despite this dramatic inability to produce tension, only $14 \%$ (8 of 58) of innervated fibers exhibited failures during 100 $\mathrm{Hz}$ nerve stimulation, and half of these exhibited only one failure during the train of 20 stimuli. If the stimulation was extended to $600 \mathrm{msec}$ (Fig. 6B, dashed line on right), failures were seen in only $18 \%$ ( 5 of 28 ) of innervated fibers. Whether stimulation lasted for 220 or $600 \mathrm{msec},<2 \%$ of the stimuli resulted in failures. Although failures were rare, EJPs were often subthreshold, consistent with weakened synaptic transmission relative to normal muscles. In addition, there was usually ( $72 \%$ of fibers) a decrease in EJP amplitude during the $220 \mathrm{msec}$ train of stimuli (Fig. 7). This synaptic depression is consistent with a general depression of synaptic transmission, rather than intermittent failure of action potential conduction.

\section{Synaptic safety factor is reduced $3 \mathrm{~d}$ after partial denervation on P14}

Our findings thus suggested a weakening of remaining synapses $3 \mathrm{~d}$ after partial denervation on P14. Although not examined in detail, other reports have hinted that such changes might occur after partial denervation in neonates (Brown et al., 1976; Gates and Ridge, 1992) as well as in adults (Thompson and Jansen, 1977; Slack and Hopkins, 1982; Ridge and Rowlerson, 1990) and in aged animals (Jacob and Robbins, 1990). The changes seen in twitch and tetanic tension and in EJPs after partial denervation on P14 could reflect decreases in synaptic safety factor. We assessed synaptic safety factor $3 \mathrm{~d}$ after partial denervation by (1) blocking AChRs using increasing concentrations of curare or (2) decreasing evoked acetylcholine release by lowering extracellular calcium concentration in a stepwise manner.

Synapses in partially denervated muscles are more sensitive to curare block

Synapses in muscles partially denervated on P14 were much more sensitive to curare block than were those in contralateral control muscles, suggesting a decreased safety factor (Fig. $8 A$ ). On average, the concentration of curare necessary to completely block evoked muscle contraction in muscles partially denervation on P14 was half that of contralateral controls (Fig. 8A, Table 2). Thus, there did not appear to be a subpopulation of synapses in partially denervated P14 muscles with normal safety factor. In contrast, although muscles partially denervated on P25-30 

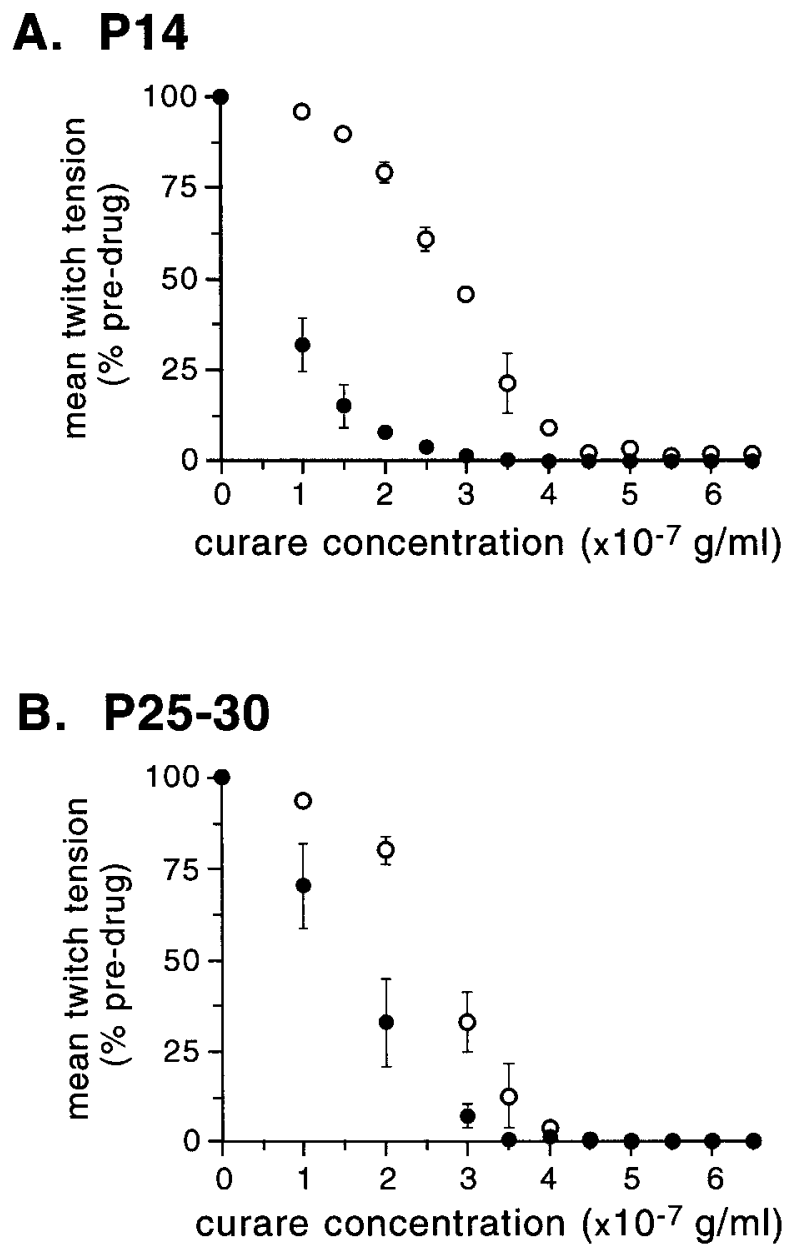

Figure 8. Curare block provides evidence of weakened synapses after partial denervation, especially in younger muscles. Twitch tension was recorded in the presence of increasing concentrations of curare $3 \mathrm{~d}$ after partial denervation on P14 $(A ; n=5)$ or on P25-30 $(B ; n=6)$. At both ages, synapses in partially denervated muscles (filled circles) were more sensitive to curare than synapses in contralateral control muscles (open circles). Synapses in muscles partially denervated on $\mathrm{P} 14(A)$ were more severely affected than were synapses in muscles partially denervated on P25-30 (B).

showed some increase in sensitivity to curare, it was less severe than in the younger muscles (Fig. $8 B$, Table 2).

To our surprise, curare sensitivity of contralateral control muscles also differed between the two age groups. A higher concentration of curare was necessary for complete block of evoked contraction in P17 contralateral muscles than in older contralateral muscles ( $p<0.001$; Table 2$)$. These data are consistent with reports that curare acts as a partial agonist on the embryonic form of AChR (Steinbach and Chen, 1995) and can actually depolarize muscle fibers in late embryonic life (Ziskind and Dennis, 1978), although one might have expected to see little evidence of these complex effects of curare as late as P17. To determine whether this apparent age dependence of curare sensitivity was attributable to contralateral effects of the partial denervation, we tested normal P17 and P26-29 soleus muscles taken from animals that had not been subjected to any previous surgery $(n=3$ per age group). As was true for muscles contralateral to partial denervation, normal P17 soleus muscles were less sensitive to curare than were normal P26-29 muscles. The curare concentration $\left(\times 10^{-7}\right.$ $\mathrm{gm} / \mathrm{ml}$ ) required for complete block of evoked muscle contraction was $6.67 \pm 0.44$ for $\mathrm{P} 17$ muscles and $4.83 \pm 0.17$ for P26-29 muscles $(p<0.02)$. These data indicate that developmental changes in the pharmacological effects of curare are still occurring as late as P17 and are not caused by partial denervation of the contralateral muscle.

Synapses in partially denervated muscles are more sensitive to reductions in extracellular calcium

In addition to its effects on postsynaptic AChRs, curare might also act on presynaptic AChRs, blocking feedback effects of acetylcholine on its own release (Bowman et al., 1988; Fu and Liu, 1997). Because of the complexity of curare effects and the developmental changes that are still taking place at P17, we used a second method of assessing synaptic safety factor. By decreasing extracellular calcium concentration in a step-wise manner (Jordan et al., 1992), we confirmed the decrease in synaptic safety factor seen in our curare experiments in a separate set of animals. Synapses in muscles partially denervated $3 \mathrm{~d}$ earlier were more sensitive to lowering extracellular calcium than were contralateral controls, and this was more striking after partial denervation on P14 than after partial denervation on P25-30 (Fig. 9, Table 2). For each decrease in calcium concentration (except the last), muscles partially denervated on P14 exhibited at least a twofold greater decrease in twitch tension than muscles partially denervated on P25-30 (Fig. 9). Together, these studies of the sensitivity of neurotransmission to curare and extracellular calcium levels provide strong evidence of weakened synapses in muscles partially denervated on P14. They do not, however, offer insight into the changes underlying this decreased synaptic safety factor.

\section{Synaptic weakening after partial denervation on P14 may be due to loss of terminal branches}

One factor underlying decreased synaptic strength could be a loss of synaptic release sites. A loss of some terminals after partial denervation has been suggested previously, based on glycogen depletion studies of adult rat lumbrical muscle (Ridge and Rowlerson, 1990). We assessed the physical relationship between nerve terminals and AChRs in whole mounts $3 \mathrm{~d}$ after partial denervation on P14 or P25-30 and in contralateral control muscles $(n=$ 7-8 animals per group). Endplates contacted by terminal or nodal sprouts were not included in this analysis. The normal neuromuscular junction displays a close apposition of presynaptic nerve terminal branches and postsynaptic AChRs (Rich and Lichtman, 1989; Balice-Gordon and Lichtman, 1993; Fig. 10E,F,O,P). In contrast, after partial denervation on P14, more than half of all innervated junctions showed a severe mismatch between nerve terminal and AChRs (Figs. $10 A-D, 11$ ), characterized by regions of AChRs without any overlying terminal branches. Although not quantified, typically at least one-fourth of the AChR plaque was apparently devoid of terminal branches. This occurred at a lower frequency in muscles partially denervated on P25-30 and was rare in contralateral control muscles (Fig. 11). Only $10.6 \%$ of endplates had any sign of polyneuronal innervation at the time of partial denervation on P14, and we excluded terminals supplied by thin axons (characterizing nodal sprouts or inputs in the process of withdrawal); therefore, these abnormal terminals (52.7\% of all innervated sites) cannot be attributable to partial denervation of individual endplates. Morphological disruption of terminals also was seen when terminals were labeled with an antibody to SV2 rather than synaptophysin (Fig. 10I-K). Because we stained terminals using antibodies against synaptic vesicle proteins, it is possible that the terminal branches were still present, but their synaptic machinery had been dismantled. We 
Table 2. Synaptic strength after partial denervation (PD) on P14 or P25-30

\begin{tabular}{|c|c|c|c|c|}
\hline & \multicolumn{2}{|l|}{ P14 } & \multicolumn{2}{|l|}{$\mathrm{P} 25-30$} \\
\hline & $\mathrm{PD}$ & Contra & PD & Contra \\
\hline Curare concentration for complete block & $3.3 \pm 0.20^{*}$ & $6.0 \pm 0.16^{* *}$ & $4.0 \pm 0.26^{* * *}$ & $4.6 \pm 0.15$ \\
\hline $\begin{array}{l}\text { Twitch tension produced in } 1 \times 10^{-7} \mathrm{gm} / \mathrm{ml} \\
\text { curare (as } \% \text { of starting tension) }\end{array}$ & $31.8 \pm 7.28^{*}$ & $96.2 \pm 1.20$ & $70.1 \pm 11.5^{* * *}$ & $93.5 \pm 1.63$ \\
\hline $\begin{array}{l}\text { Twitch tension produced in } 1.2 \mathrm{~mm} \text { calcium } \\
\text { (as \% of starting tension) }\end{array}$ & $35.5 \pm 6.87^{*}$ & $93.1 \pm 2.62$ & $78.9 \pm 13.20$ & $93.8 \pm 1.75$ \\
\hline
\end{tabular}

Data are presented as mean \pm SEM. For curare experiments, $n=5$ P14 animals, $n=6$ P25-30 animals; for calcium experiments, $n=4$ muscles per group.

${ }^{*},{ }^{* *}$ Significantly different from contralateral controls (Contra), ${ }^{*} p<0.001 ;{ }^{* * *} p<0.05$.

**Significantly different from P25-30 contralateral controls, $p<0.001$.

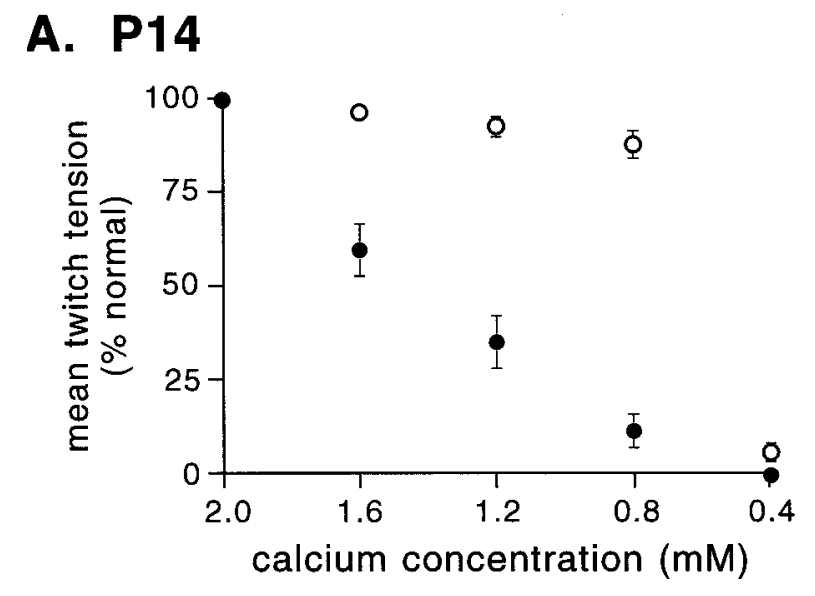

B. $\mathbf{P} 25-30$

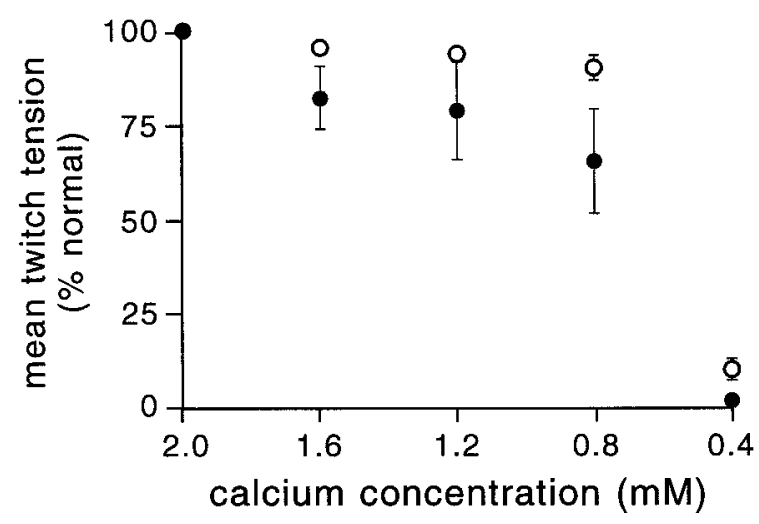

Figure 9. Lowering calcium levels provides evidence of decreased synaptic safety factor after partial denervation, especially in younger muscles. Twitch tension was recorded in the presence of decreasing levels of calcium 3 d after partial denervation on P14 $(A ; n=4)$ or on P25-30 (B; $n=4$ ). At both ages, synapses in partially denervated muscles (filled circles) were more sensitive to lowering calcium levels than synapses in contralateral control muscles (open circles). Synapses in muscles partially denervated on P14 $(A)$ were more severely affected than were synapses in muscles partially denervated on P25-30 (B).

have not yet distinguished between these two possibilities, but either would suggest that a presynaptic change accompanies the synaptic weakening seen after partial denervation on P14. Schwann cells at disrupted junctions typically covered the remaining terminal but not the entire AChR plaque (Fig. 10A-D).
It is formally possible that the disrupted synapses seen after partial denervation are new synapses being formed by nodal sprouts (although with unexpectedly thick axons), which are therefore immature in structure and in strength. This would be consistent with the fade seen during high-frequency stimulation but can be ruled out by a number of observations. First, if terminals newly formed by sprouts were weak, but terminals present at the time of partial denervation were unaffected, one would expect a component of the twitch tension in curare or lowered calcium to behave like normally innervated muscle (Rochel and Robbins, 1988). We did not see evidence of such a subpopulation of normal terminals in muscles partially denervated on P14. Second, if existing terminals were unaffected, we would expect no decrease in twitch or tetanic tension, but a slight increase reflecting the contribution of new, albeit weaker, synapses. Instead, we saw a trend toward decreased twitch tension and a striking decrease in tetanic tension after partial denervation on P14. Third, in an additional group of partially denervated P25-30 muscles, we used an antibody to protein zero, a myelinspecific protein, instead of labeling neurofilament. In these muscles, we observed examples of severely disrupted terminals innervated by myelinated axons (Fig. $10 L-N$ ), clearly ruling out the possibility that all disrupted terminals were newly forming terminals at the end of misidentified nodal sprouts. In summary, neonatal partial denervation sets in motion processes that disrupt uninjured terminals present in the muscle at the time of partial denervation. A loss of potential release sites may underlie the decreased synaptic efficacy of motor terminals in partially denervated muscles.

\section{DISCUSSION}

The present studies shed light on the relatively poor response of neonatal motoneurons to partial denervation of their target muscle and have implications for our understanding of developmental synapse elimination. Our results are consistent with the hypothesis that the death of terminal Schwann cells at denervated endplates in neonates removes a critical stimulus for terminal sprouting, which is the primary means by which fibers are reinnervated in partially denervated adult soleus muscles (Brown and Ironton, 1978). We also found evidence of severe synaptic disruption after partial denervation on P14, suggesting that some terminals retract after partial denervation in development.

The limited expansion of neonatal motor units after partial denervation is not attributable to their already enlarged size

In the initial studies of neonatal partial denervation, muscles were partially denervated before $\mathrm{P} 7$, when motor units are substantially 

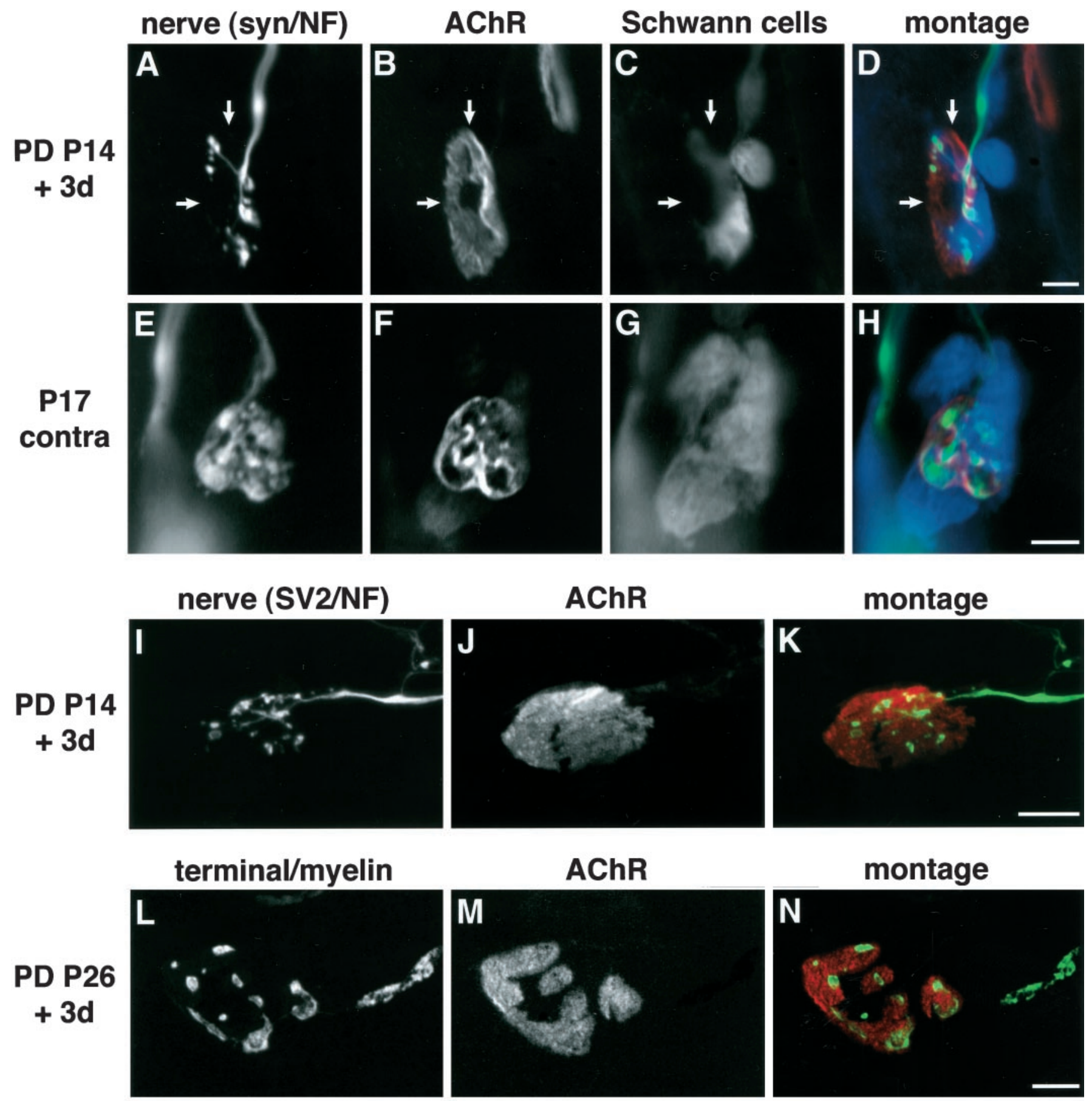

AChR
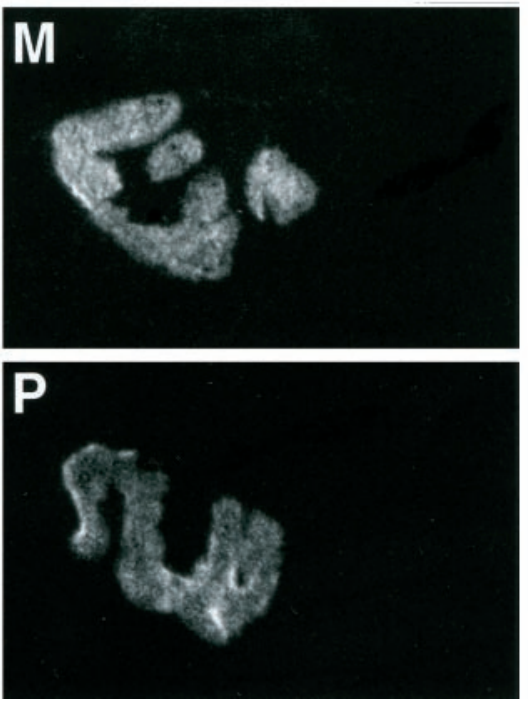

montage
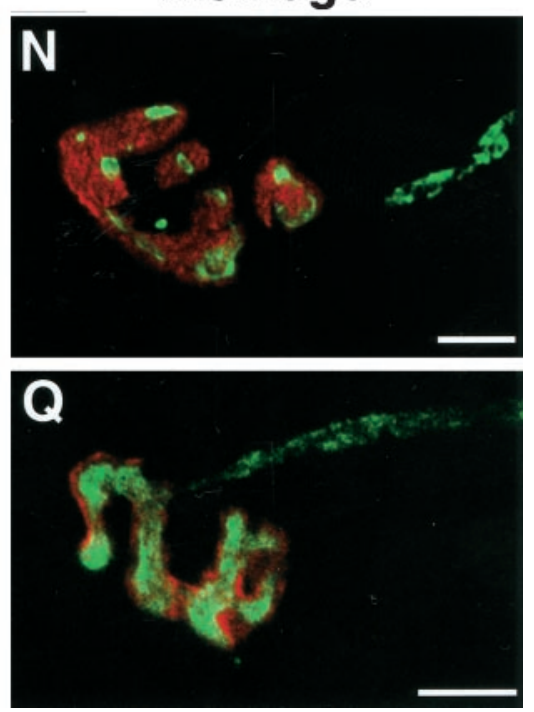

Figure 10. Terminal morphology is disrupted $3 \mathrm{~d}$ after partial denervation $(P D)$. $A-H$, Fluorescent photomicrographs of neuromuscular junctions from a muscle partially denervated $3 \mathrm{~d}$ earlier on P14 $(A-D)$ and from the contralateral control muscle $(P 17$ contra; $E-H)$. Junctions were triple-labeled with anti-neurofilament $(N F)$ and anti-synaptophysin (syn) to visualize nerve processes $(A, E), \alpha$-bungarotoxin to visualize AChRs $(B, F)$, and anti-S100 to visualize Schwann cells $(C, G)$. In the color montages $(D, H)$, nerve processes are green, AChRs are red, and Schwann cells are blue. In control muscles, terminal branches fully covered AChR plaques, whereas in partially denervated muscles, there were often regions of AChR without apposed terminal branches $(A-D$, arrows). Schwann cells (only partially in focus in this photomicrograph) at disrupted junctions maintained (Figure legend continues) 


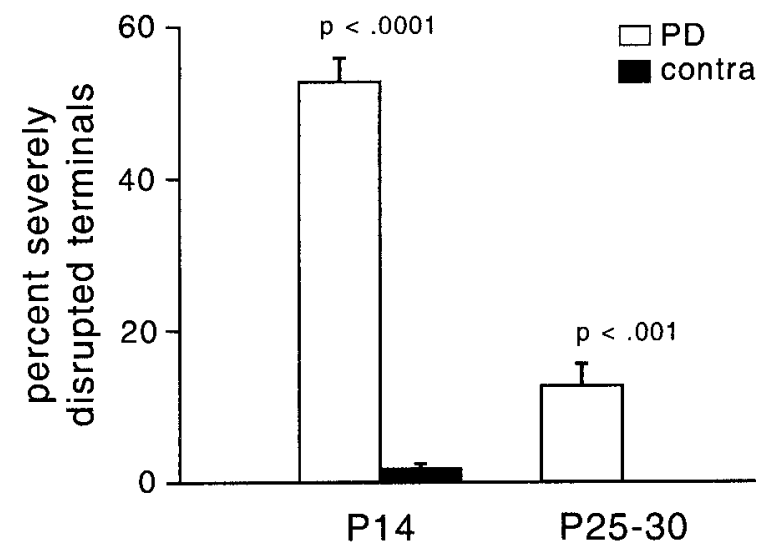

Figure 11. Immature nerve terminals are morphologically disrupted by denervation of neighboring fibers in the muscle. Muscles were processed immunohistochemically (see Materials and Methods) $3 \mathrm{~d}$ after partial denervation $(P D)$ on P14 $(n=8)$ or on P25-30 $(n=7)$. Endplates in which extensive regions of AChRs were not covered by terminal branches (see Fig. 10) were categorized as being severely disrupted. Typically, at least one-fourth of the AChR plaque had no apposing terminal branches. This analysis excluded endplate sites contacted by a nodal or terminal sprout. In muscles partially denervated on P14, more than half of all terminals were severely disrupted. Severely disrupted terminals were less common in muscles partially denervated on P25-30 and were extremely rare in contralateral control muscles (contra). No bar is seen for contralateral muscles at P25-30, because values were all zero. Two-way interaction, $p<0.0001$.

larger than in adulthood. It has been suggested that neonatal motoneurons are less able to reinnervate denervated fibers because they are already maintaining a large number of terminals. The present data argue strongly against this hypothesis. We partially denervated the soleus muscle at the end of developmental synapse elimination (Brown et al., 1976), when soleus motor units have decreased to their adult size. Motor units in muscles partially denervated on P14 did not expand as much as units in partially denervated adult muscles. Studied in a different context, Fisher et al. (1989) found no difference in motor unit expansion after partial denervation (by ventral rhizotomy) of the soleus on P4-6 or on P17-19. Thus, immature motoneurons fail to reinnervate denervated fibers as effectively as mature motoneurons even if they start at the same motor unit size.

\section{Death of terminal Schwann cells after partial denervation may underlie the limited expansion of neonatal motor units}

Schwann cells are necessary for axonal regeneration in peripheral nerve (Enver and Hall, 1994). Previous work also suggested that terminal Schwann cells at denervated endplates are important in motoneuron sprouting after partial denervation (Son and Thompson, 1995b; Trachtenberg and Thompson, 1997). Three days after partial denervation of adult soleus muscles, most $(\sim 70 \%)$ of the terminal sprouts that reach denervated endplate sites are found in association with processes extended only by
Schwann cells at the denervated site (Son and Thompson, 1995b). However, partial denervation during early postnatal life caused the death of terminal Schwann cells at denervated endplates. If these cells are important in the motoneuron sprouting response, one would expect to see a deficit in terminal sprouting by neonatal motoneurons.

As expected (Brown and Ironton, 1978), partial denervation of the soleus muscle on P25-30 resulted in robust terminal sprouting, but terminal sprouting was absent in muscles partially denervated on P14. Young motoneurons did not appear to be less competent than mature motoneurons at sprouting, because they were capable of extending nodal sprouts. An appealing explanation for the difference in terminal and nodal sprouting after partial denervation on $\mathrm{P} 14$ arises from the observation that after neonatal denervation, Schwann cell death is more severe at endplates than in the intramuscular nerves (Trachtenberg and Thompson, 1996). After partial denervation on P14, reactive Schwann cells are present to induce sprouts from axons at nodes of Ranvier but are not present to induce sprouts from terminals, which could explain the difference in nodal and terminal sprouting by immature motoneurons. Because terminal sprouting is the primary means by which motor unit expansion occurs in the soleus muscle (Brown and Ironton, 1978), the lack of Schwann cell-induced terminal sprouting may account for the failure of immature motor units to expand after partial denervation.

\section{Extensive nodal sprouting may contribute to the disruption of existing terminals}

Motor units in muscles partially denervated on P14 do not increase in size as much as mature motor units. This indicates that nodal sprouts do not fully compensate for the lack of terminal sprouts. One possible explanation is that nodal sprouts are more metabolically costly to the motoneuron than are terminal sprouts, which predominate in more mature muscles. The extensive nodal sprouting seen $3 \mathrm{~d}$ after partial denervation therefore may not be maintained. In addition, metabolic support of existing terminals may be compromised by extensive nodal sprouting. If so, a greater prof usion of nodal sprouts in immature muscles might explain the greater synaptic disruption seen after partial denervation on P14. Another contributing factor could be that synapses are inherently less stable during and shortly after the period of synapse elimination than in adulthood. This is consistent with the greater sensitivity of developing neuromuscular junctions to disruption by neuregulin treatment (Trachtenberg and Thompson, 1997) and is attractive in light of the dynamic nature of neuromuscular junctions during early postnatal development (Gan and Lichtman, 1998). In addition, reactive Schwann cells can cause similar disruption of otherwise normal neuromuscular junctions (Trachtenberg and Thompson, 1997). However, the fact that we saw greater terminal disruption after partial denervation on P14 (when most Schwann cells die) than on P25-30 (when Schwann cells become reactive) argues against a direct role for reactive Schwann cells in the changes seen after neonatal partial denervation.

\section{$\leftarrow$}

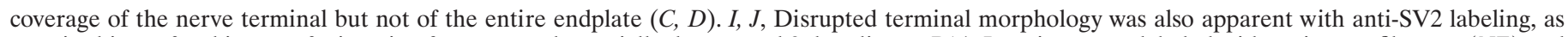

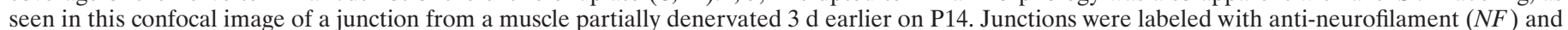

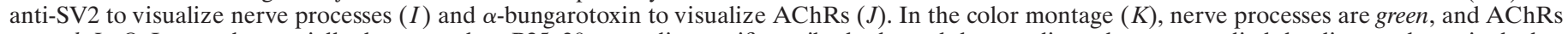

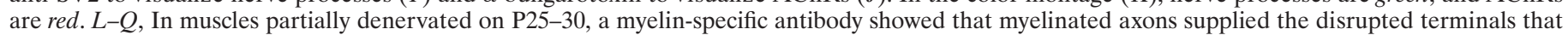

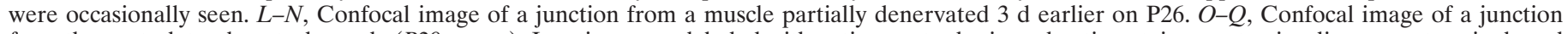

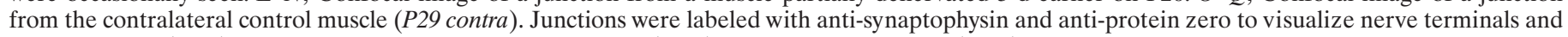

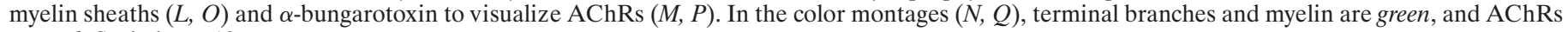
are red. Scale bars, $10 \mu \mathrm{m}$. 


\section{Presynaptic changes that occur after partial denervation on P14 result in decreased synaptic safety factor}

We found striking decreases in synaptic efficacy after partial denervation in development, with lesser effects after partial denervation on P25-30. Three days after partial denervation on P14, stimulation of isolated motor units produced decreased tetanic tension. The tension evoked by repetitive nerve stimulation also diminished, or faded, during the $1500 \mathrm{msec}$ stimulus. This fade, especially striking during high-frequency stimulation, and the decreased tetanic tension were not due to muscle fatigue or conduction block but appeared instead to be due to decreased synaptic safety factor. Synapses in muscles partially denervated $3 \mathrm{~d}$ earlier on P14 were much more sensitive to curare block and to lowered calcium levels than were synapses in muscles partially denervated on P25-30. Thus, synapses formed by immature motoneurons became weaker $3 \mathrm{~d}$ after partial denervation of their target muscle. This was attributable, at least in part, to the loss of functional release sites evidenced by decreased labeling with antibodies to the synaptic vesicle proteins synaptophysin and SV2. Although a significant portion of terminals looked normal morphologically, our physiological studies suggested that all terminals in muscles partially denervated on P14 were functionally impaired. Thus, there may have been other changes that also affected synaptic function.

\section{Implications for understanding developmental synapse elimination}

Early studies of neonatal partial denervation were designed to test the hypothesis that competition between motor terminals drives developmental synapse elimination (Brown et al., 1976; Thompson and Jansen, 1977; Betz et al., 1980; Fladby and Jansen, 1987; Gates and Ridge, 1992). These experiments led to two major conclusions. First, competition between motor terminals is an important component of developmental synapse elimination. Second, something intrinsic to motoneurons (not competitionbased) also contributes to synapse elimination. Our findings suggest that the latter conclusion is not justified. We found that the terminals of immature motoneurons that continue to innervate the soleus muscle after partial denervation do not remain normal. Thus, what was seen as an intrinsic tendency of motoneurons to withdraw synapses may instead be a process secondary to the denervation of neighboring muscle fibers. The present findings also raise more general concerns about the use of partial denervation in development to study synapse elimination. Although not directly injured, motoneurons remaining after partial denervation are not completely normal. The synapse elimination that occurs after partial denervation may not be precisely the same as normal developmental synapse elimination.

Although the changes seen in terminals after partial denervation on P14 are reminiscent of those seen in terminals being lost during developmental synapse elimination, there are critical differences. During normal development and after reinnervation, synapses become weaker before being eliminated (Colman et al., 1997), but evidence suggests that this is attributable primarily to a decrease in postsynaptic AChR density (Rich and Lichtman, 1989; Balice-Gordon and Lichtman, 1993; Colman et al., 1997). We did not observe any obvious changes in AChR labeling $3 \mathrm{~d}$ after partial denervation, but this was not studied in a quantitative manner. Nevertheless, it is possible that although the factors triggering these events differ, the mechanisms underlying the apparent loss of terminal branches after partial denervation on P14 may be related to those underlying the loss of terminal branches that occurs during synapse elimination (Gan and Lichtman, 1998). Our results are consistent with the hypothesis that increased nerve growth at some sites along an axon can cause the loss of terminal branches at other sites. Perhaps after partial denervation on P14, we observe an exaggerated version of what normally occurs during developmental synapse elimination, namely that the growth of some terminals of a motoneuron weakens other terminals, placing them at a competitive disadvantage (Colman et al., 1997) and resulting in their elimination.

\section{REFERENCES}

Balice-Gordon RJ, Lichtman JW (1993) In vivo visualization of the growth of pre- and postsynaptic elements of neuromuscular junctions in the mouse. J Neurosci 10:894-908.

Betz WJ, Caldwell JH, Ribchester RR (1980) The effects of partial denervation at birth on the development of muscle fibres and motor units in rat lumbrical muscle. J Physiol (Lond) 303:265-279.

Bowman WC, Marshall IG, Gibb AJ, Harborne AJ (1988) Feedback control of transmitter release at the neuromuscular junction. Trends Pharmacol Sci 9:16-20.

Brown MC, Ironton R (1978) Sprouting and regression of neuromuscular synapses in partially denervated mammalian muscles. J Physiol (Lond) 278:325-348.

Brown MC, Jansen JKS, Van Essen D (1976) Polyneuronal innervation of skeletal muscle in new-born rats and its elimination during development. J Physiol (Lond) 261:387-422.

Brown MC, Holland RL, Ironton R (1980) Nodal and terminal sprouting from motor nerves in fast and slow muscles of the mouse. J Physiol (Lond) 306:493-510.

Close R (1964) Dynamic properties of fast and slow skeletal muscles of the rat during development. J Physiol (Lond) 173:74-95.

Close R (1967) Properties of motor units in fast and slow skeletal muscles of the rat. J Physiol (Lond) 193:45-55.

Colman H, Nabekura J, Lichtman JW (1997) Alterations in synaptic strength preceding axon withdrawal. Science 275:356-361.

Enver MK, Hall SM (1994) Are Schwann cells essential for axonal regeneration into muscle autografts? Neuropathol Appl Neurobiol 20:587-598.

Fisher TJ, Vrbová G, Wijetunge A (1989) Partial denervation of the rat soleus muscle at two different developmental stages. Neuroscience 28:755-763.

Fu WM, Liu JJ (1997) Regulation of acetylcholine release by presynaptic nicotinic receptors at developing neuromuscular synapses. Mol Pharmacol 51:390-398.

Gan W-B, Lichtman JW (1998) Synaptic segregation at the developing neuromuscular junction. Science 282:1508-1511.

Gates HJ, Ridge RM (1992) The importance of competition between motoneurones in developing rat muscle; effects of partial denervation at birth. J Physiol (Lond) 445:457-472.

Gordon T, Yang JF, Ayer K, Stein RB, Tyreman N (1993) Recovery potential of muscle after partial denervation: a comparison between rats and humans. Brain Res Bull 30:477-482.

Guth L, Samaha FJ (1970) Procedure for the histochemical demonstration of actomyosin ATPase. Exp Neurol 28:365-367.

Hoffman H (1950) Local re-innervation in partially denervated muscle: a histo-physiological study. Aust J Exp Biol Med Sci 28:383-397.

Jacob JM, Robbins N (1990) Differential effects of age on neuromuscular transmission in partially denervated mouse muscle. J Neurosci 10:1522-1529.

Jansen JKS, Fladby T (1990) The perinatal reorganization of the innervation of skeletal muscle in mammals. Prog Neurobiol 34:39-90.

Johnson GD, Nogueira Araujo GMdeC (1981) A simple method of reducing the fading of immunofluorescence during microscopy. J Immunol Methods 43:349-350.

Jordan CL, Pawson P, Arnold AP, Grinnell AD (1992) Hormonal regulation of motor unit size and synaptic strength during synapse elimination in the rat levator ani muscle. J Neurosci 12:4447-4459.

Krnjevic K, Miledi R (1957) Adrenaline and failure of neuromuscular transmission. Nature 180:814-815. 
Kugelberg E (1976) Adaptive transformation of rat soleus motor units during growth. J Neurol Sci 27:269-289.

Liley AW (1956) An investigation of spontaneous activity at the neuromuscular junction of the rat. J Physiol (Lond) 132:650-666.

Lingle CJ, Steinbach JH (1988) Neuromuscular blocking agents. Int Anesthesiol Clin 26:288-301.

Love FM, Thompson WJ (1998) Schwann cells proliferate at rat neuromuscular junctions during development and regeneration. J Neurosci 18:9376-9385.

Lubischer JL, Thompson WJ (1997) Partial denervation of soleus muscle results in an age-dependent decrease in the efficacy of the remaining neuromuscular junctions. Soc Neurosci Abstr 23:1720.

Redfern PA (1970) Neuromuscular transmission in new-born rats. J Physiol (Lond) 344:89-111.

Rich MM, Lichtman JW (1989) In vivo visualization of pre- and postsynaptic changes during synapse elimination in reinnervated mouse muscle. J Neurosci 9:1781-1805.

Ridge RMAP, Rowlerson A (1990) Sprouting motoneurons break as well as make contacts in partially denervated rat muscle. J Physiol (Lond) 425:15P.

Rochel S, Robbins N (1988) Effect of partial denervation and terminal field expansion on neuromuscular transmitter release and nerve terminal structure. J Neurosci 8:332-338.
Slack JR, Hopkins WG (1982) Neuromuscular transmission at terminals of sprouted mammalian motor neurones. Brain Res 237:121-135.

Steinbach JH, Chen Q (1995) Antagonist and partial agonist actions of $d$-tubocurarine at mammalian muscle acetylcholine receptors. J Neurosci 15:230-240.

Son Y-J, Thompson WJ (1995a) Schwann cell processes guide regeneration of peripheral axons. Neuron 14:125-132.

Son Y-J, Thompson WJ (1995b) Nerve sprouting in muscle is induced and guided by processes extended by Schwann cells. Neuron 14:133-141.

Thompson WJ (1978) Reinnervation of partially denervated rat soleus muscle. Acta Physiol Scand 103:81-91.

Thompson WJ, Jansen JKS (1977) The extent of sprouting of remaining motor units in partly denervated immature and adult rat soleus muscle. Neuroscience 2:523-535.

Trachtenberg JT, Thompson WJ (1996) Schwann cell apoptosis at developing neuromuscular junctions is regulated by glial growth factor. Nature 379:174-177.

Trachtenberg JT, Thompson WJ (1997) Nerve terminal withdrawal from rat neuromuscular junctions induced by neuregulin and Schwann cells. J Neurosci 17:6243-6255.

Ziskind L, Dennis MJ (1978) Depolarising effect of curare on embryonic rat muscles. Nature 276:622-623. 